\title{
Instructors' experiences of web based synchronous communication using two way audio and direct messaging
}

\author{
Elizabeth Murphy and Justyna Ciszewska-Carr \\ Memorial University of Newfoundland
}

This paper reports on an exploratory case study designed to gain insight into instructors' experiences with web based synchronous communication using two way audio and direct messaging. We conducted semi-structured interviews with eight instructors who used Elluminate Live in their web based, asynchronous courses in Education, Nursing, and Social Work at a Canadian university during the Winter 2004-05. We grouped the findings into two categories. The first category relates to use of text based communication or direct messaging (DM). We subdivided this category as follows: trouble shooting versus teaching; and public versus private conversations. The second category relates to use of voice based communication or audio conferencing (two way audio) subdivided into four sub-categories as follows: talkers versus listeners; patience versus prompting; whole group versus breakout groups; and two way versus one way communication. Use of text based messaging and two way audio raised issues of the need to divide one's attention and to promote student-student interaction. Implications for research and practice are presented.

\section{Introduction}

Synchronous interactions have been described as "the poor cousin of asynchronous interactions" (Coghlan, 2004, Introduction section). In the past, use of synchronous tools has been characterised by challenges. These relate to scheduling, high equipment costs, bandwidth requirements, as well as limited tool accessibility, stability, and reliability (Chou, 2002; Coghlan, 2004; Slack, Beer, Armitt \& Green, 2003). As a result, online courses have most often favoured asynchronous interactions. Yet, this approach has often resulted in access to "clunky" and "unsexy" text based chat tools that serve as little more than "lightweight distractions" or "social meeting spaces" (Coghlan, 2004, Introduction section). 
In terms of research on the use of synchronous communication tools, thus far, a number of studies have explored the use of text based chats (e.g. Dykes \& Schwier, 2003; Lobel, Neubauer \& Swedburg, 2005; Murphy \& Collins, 1997; Slack et al., 2003; Schwier \& Balbar, 2002). Some studies have explored audio conferencing (e.g. De Schutter, Fahrni \& Rudolph, 2004; Levy \& Kennedy, 2004; Nobes, 2003) and others, video conferencing (for reviews, see Anderson \& Rourke, 2005; Knolle, 2002; MacLaughlin, Supernaw \& Howard, 2004). This research has most often focused on investigations of a single mode of the technology such as chat, audio or video conferencing. For example, Nicholson (2002) and Hrastinski (2005) inquired into the use of synchronous communication tools in the context of asynchronous courses. Their focus was on text based synchronous tools only.

As a result of the growth of accessibility and affordability of equipment and bandwidth, web based synchronous communication is now becoming more common in distance education (Chou, 2002; Coghlan 2004; Knolle, 2002). New online synchronous communication environments such as Elluminate Live, HorizonLive, and Lyceum support multiple channels for communication and combine use of text based messaging in conjunction with other tools and features such as audio and/or video conferencing.

This recent growth highlights a need for a parallel interest in research on use of the technology in contexts of distance courses. The study reported on in this paper addresses this need through its focus on synchronous communication in distance courses at the university level. The purpose of the study was to gain insight into instructors' experiences with two way audio and text based direct messaging (DM). The exploratory study focused on the case of integration of a web based, synchronous communication environment called Elluminate Live into distance courses at a Canadian university.

\section{Methodology}

\section{Case study}

We approached the study with no other research question, hypothesis, or purpose than to gain insight into the instructors' experiences in these environments. As Yin (2003) explains, exploratory case studies do not include any prior propositions that might determine which specific aspects of the problem under investigation should be examined. Thus, our data collection preceded the formulation of research questions. The latter are proposed at the end of the study where the goal was to "develop pertinent hypothesis and propositions for further inquiry" (Yin, 2003, p. 6). 


\section{Context}

The study focused on the integration of Elluminate Live (ELive) Academic Edition 6.0 into asynchronous distance courses at Memorial University of Newfoundland in Canada during the Winter of 2004-05. The integration was initiated and coordinated by Distance Education Learning Technologies (DELT), which is the unit of the University responsible for the design and delivery of distance courses. The decision to introduce this technology was partly motivated by the need to replace teleconferencing with a web based technology, and by a goal of giving instructors more choice and flexibility in delivery methods. The asynchronous courses in which ELive was integrated relied on use of WebCT Campus Edition Version 4.1. The tools within this learning management system support communication and interaction that is solely text based. Additionally, with the exception of the chat feature, the tools support only asynchronous communication.

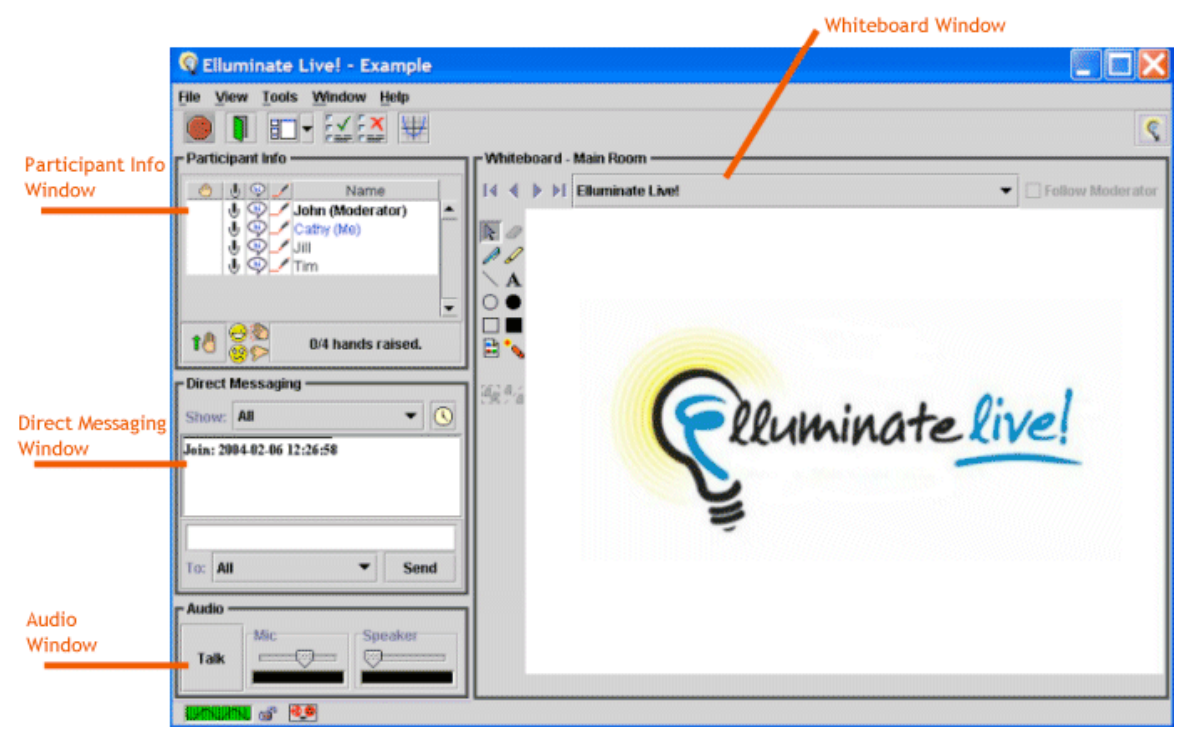

Figure 1: Version of Elluminate Live used in the context of the case study (Elluminate Live, 2001-2006)

Unlike WebCT or the asynchronous portion of the course, ELive supported students' and instructors' synchronous communication using both text and voice exchanges. There was no visual or video based interaction. The version being used at the time supported half duplex, two way synchronous audio conferencing, which allows one person to speak at a time. ELive's Academic Version 7.0 allows communication between up to 
four individuals at one time. This version was not available at the institution when we conducted the case study. In addition to audio conferencing, students could engage in text based communication with the instructor or privately with one another through a direct messaging (DM) tool. Interaction could also take place in breakout rooms for work in smaller groups. Other tools available included a whiteboard, an application sharing tool, as well as a 'hand-raising' and polling feature (see http: / / www.elluminate.com/).

\section{Participants}

All instructors who would be teaching distance courses in the Winter 2005 were invited by DELT to incorporate ELive into their courses for one 2 hour e-lecture, e-presentations, online office hours, or for any other purpose. These ELive sessions had to be scheduled in the evenings because of licensing requirements. During the day, the licensed 'seats' or spaces were filled by secondary students completing distance education courses. The number of sessions scheduled for each course varied from only one ELive meeting in the first week of the semester to sessions held every week of the twelve week course.

For our case study, we focused on eight of these ten instructors who responded to DELT's invitation to use ELive. The two instructors who did not serve as participants were the researcher and one instructor who left the University before the study was conducted. Six of the instructors were in Education, one was in Nursing and another in Social Work. With the exception of two of the eight courses, all were at the graduate (Master's) level. All eight instructors had prior experience teaching distance courses. Five of them had prior experience using teleconferencing for synchronous communication within distance courses. One individual had also used other forms of synchronous technology, such as two way television and one way video.

Technical training was conducted by DELT in two stages. The first stage involved individual meetings with an instructional design specialist during which instructors became familiar with the structure and use of the software. The second stage involved conducting a trial session. Some instructors also requested student training sessions at the beginning of the semester. Student sessions involved a demonstration of ELive features as well as equipment checks. Students were also provided with an opportunity to do mechanical checks half an hour prior to each session.

\section{Interviews}

Our goal was to gain insight into instructors' experiences with web based synchronous communication within asynchronous distance courses. We 
chose to conduct interviews as a means of gaining insight into their experiences. All interviews were conducted in the Spring following the Winter integration of the technology. Each interview lasted 45-60 minutes. They were semi-structured as opposed to structured because the exploratory nature of the study meant we could not anticipate the types of experiences that instructors might highlight. Semi-structured interviews also allowed us some flexibility to probe more deeply or broadly and to seek clarification or alternative perspectives. The interviews were semistructured as opposed to unstructured in order to facilitate comparisons between interviewees. The structure of the interviews was evident in our focus on three areas: the context in which ELive was used; the value and challenges of using web based synchronous communication; and future uses of synchronous technology. Within these three areas, our questions varied slightly from interview to interview. Some of the questions included "In what course did you use Elluminate Live?", "What did you hope to get out of the synchronous sessions?", "What were the challenges of the experience?", and "If you were to use the technology again, would you do anything differently?"

\section{Analysis}

Data analysis was driven by a grounded theory approach (Glaser, 1992). Instead of testing pre-existing theoretical notions, we examined the data inductively. We began by reading the interview transcripts to "expose the thoughts, ideas, and meanings contained therein" (Strauss \& Corbin, 1998, p. 102). Coding involved a line by line analysis in the course of which we made constant comparisons between incidents reported by instructors (Glaser, 1992). Patterns of similarities between incidents were examined, conceptualised, and classified into categories (Charmaz, 2000; Strauss \& Corbin, 1998). We selected the labels or names for the categories to reflect their principal properties. Reporting of the data relied on verbatim use of participants' quotes to present their voice, reality, and perspectives so that they speak for themselves (Glaser, 1992). We assigned pseudonyms to these participants. The discussion involved "weaving in the literature" against which findings of this study are compared (Glaser, 1992, p. 76).

\section{Findings}

We grouped the findings into two categories. The first category relates to use of text based communication or direct messaging (DM). We subdivided this category into two sub-categories as follows: trouble shooting versus teaching, and public versus private conversations. The second category relates to use of voice based communication or audio conferencing (two way audio). We subdivided this category into four sub-categories as 
follows: talkers versus listeners; patience versus prompting; whole group versus breakout groups; and two way versus one way communication.

\section{Trouble shooting versus teaching}

Instructors frequently used DM as a means of dealing with technical problems rather than for implementing pedagogical strategies. The reliance on DM for this purpose was particularly evident in cases where students were experiencing problems communicating with two way audio. Students and instructors relied on DM to report difficulties or to resolve problems, for instance when the microphones were not working. Brian described the experiences of one student whose audio consistently did not work, and who, as a result, was "relegated to the instant messaging." The student's reliance on DM in this context did not appear to hinder her participation in the class. Yet, Brian observed that "she must have had to make an extraordinary effort and type like mad to keep up."

The advantage of using DM as a technical backup was overshadowed by the disadvantage of simultaneous use of the tool for technical and pedagogical purposes. As one individual explained, "that kind of troubleshooting at the same time as doing everything else ... was very challenging." In Emily's class, for example, some students had difficulties using the audio component and "kept sending ... text messages saying: I can't participate. I'm here, but I can't say anything." Emily expressed concerns and frustration with having to follow the written communication in DM and, at the same time, address students who were having problems while she was lecturing using the two way audio. She was disoriented by the need to juggle the pedagogical and the technical use of the tool. As she explained: "there were almost like two activities happening at the one time: one which was related to the technological problems and the other related to the course."

\section{Public versus private conversations}

In spite of the inconveniences that arose from using DM as a technical backup, this feature of ELive was perceived by some instructors as an effective communication tool. Roger, for example, highlighted the benefit of DM for asking questions or communicating privately without having "to interfere with what was being said." He commented that "if the student wanted to say something to Bob, they could just type to Bob as opposed to having to say it publicly.... So the student could have more privacy." Adam also appreciated the opportunity afforded by DM. For him, the comments posted by students using DM served as triggers to involve them in the discussion. Students in his sessions "would just type" when they 
wanted to make "a quick little interjection," and Adam would ask them to elaborate on these brief comments and give them access to the mike.

While Roger's and Adam's comments highlight some of the positive experiences instructors had with DM, others, like Emily, highlighted the distraction that resulted when students were "just kind of chatting back and forth in an informal way." She referred to students "talking about things in the course but things that they shouldn't necessarily be talking about while another person was speaking." David described how, in some instances, students would use DM for social, non-course related communication to talk to each other while the presentations were going on. Similarly, Roger recounted that "probably 20 percent of the time, [students] might have been sociable" and exchanged notes like "Hi Bill... How is the course going?'" Neil commented that he "basically ignored" these exchanges, although he interjected on occasion to ask "Do you guys want to talk about Saturday night or do you want to talk about the class tonight?" Like Neil, David reported that he sometimes needed to focus students" attention away from the DM and "type in a message... to remind them - are they paying attention?"

Emily's reaction to the use of DM was similar to that of Neil and David. To describe her experience, she used the analogy of "having people in your class whispering to each other while the class is going on". She explained that "A lot of these people knew each other from previous courses" and wanted to have "little side conversations." Although she found it distracting, Emily did not stop private communication between students because she wanted to avoid making the use of the new technology "a very restrictive experience." In the future, however, she plans to introduce "some more rules around how to communicate... and set restrictions about text messaging" to avoid a similar experience.

\section{Talkers versus listeners}

In addition to DM, students and instructors could also communicate with each other using the two way audio. However, not all students took advantage of this tool. In fact, the levels of participation using the two way audio differed among individual students with some speaking more than others. Roger described that, in his class, "there were many students who listened but never really asked any questions or contributed a whole lot to the discussion." Brian had a similar experience with regards to the participation of his students. He noted that "certain people would ask a lot of questions. Certain people were interested in talking a lot." Neil also remarked on the tendency for some students to speak more than others. He argued that this difference was simply due to the fact that "some students like to talk" and that, furthermore, "some students like to talk too much" 
which meant that "it was usually pretty much the same people who would speak."

Brian argued that this difference in participation levels was "pretty much the same as any other course in the classroom [where] some people ... are talking all the time to the exclusion of others." David attributed these differences in participation to personal differences among students noting that "there are talkers and there are listeners". He commented that these differences did not bother him because "the fact that they're not talking doesn't mean that they're not learning... and that's true whether it's a face to face class or an online class... In any situation, some people are going to talk more than others..." Like David, Adam was not concerned about the varied levels of participation. He argued that:

while they [students] are listening, they are engaged in their own ideas as well. They might not express them because they might not feel comfortable doing it but they still come back after the course is over and say: 'I learned a lot. I thought an awful lot about the things that were going on.'

\section{Patience versus prompting}

Most of the instructors did not express concern about the varying levels of participation from students. All, however, used certain strategies to encourage such participation. For example, they adopted different approaches to dealing with the periods of silence that occasionally characterised communication using the two way audio. In Neil's classes, there were a few quiet moments but, as he explained, he was used to those from teleconferencing. To break the silence and engage students, he would make comments such as: "Is anybody alive out there?" These types of prompts proved effective in eliciting participation. At the same time, Neil explained that, in an online environment, instructors "have to learn to wait." While in a face to face classroom they can see that "someone might want to say something or they look eager," such visual cues are lacking in an online class. For this reason, Neil's preferred reaction to silence was patience rather than prompting.

In Emily's course, adopting the strategy of giving students some time to think about a response proved effective. After posing a question, she would "give it a minute or... a few seconds for people to think about it and usually their hands would go up." Audrey noted that this strategy may require some patience on the part of the instructor because "sometimes... you'd sit there for ages and no hands would come up." However, the strategy worked for her because she had "a great tolerance for silence."

In cases when students did not respond, some instructors encouraged participation by asking a question to the whole group of students such as 
"Does anybody want to add anything?" David explained that, after a period of silence, he might ask an individual student to contribute or ask students if "they [have] all gone to sleep or something." According to one instructor, this approach seemed to encourage some participation from students. In other instances, however, it did not promote any meaningful interaction. Roger observed that "sometimes... [students] were just asking the question out of pity for the instructor". Adam reported that, in his course, the amount of prompting decreased over time. He noted that, although he never prompted students a lot, "as time went on, it certainly got less."

Some instructors chose to prompt individual students. Neil, for example, would ask one student to elaborate on a problem mentioned in an email "because that might be an issue that the whole class is interested in". Adam's approach was to "wait a little while" and then to engage students who were ordinarily quiet. He would ask individual students questions such as "Bob, what do you think of this?" or "Do you agree with that, Sarah, or would you do something else?" A few weeks into the course, however, such prompting was no longer needed as students would answer independently. Like other instructors, Audrey resorted to addressing individual students. At the same time, she gave them the option of not responding. She explained that because the tutorials were voluntary, she could not require students to actively participate. For this reason, she told students: "if I come to you and you don't want to discuss something just say so."

Instead of addressing individual students, Emily preferred to prompt the group as a whole. On several occasions during her session, she asked the group if anyone else wanted to make a comment. She did not, however, "specifically go after" students who did not speak. Also, David preferred to prompt the entire group instead of individuals. Only occasionally did he ask somebody a question directly to get them involved, but he explained that he was "not big on that kind of intimidation". For Neil, participation in the discussions was the students' individual choice and therefore he "would let people make their own decision to speak".

\section{Two way versus one way communication}

The patterns and directions of communication varied from one course to another. Emily described "most of the verbal conversations" in her course as being student to instructor and vice versa. This flow of communication resulted from the fact that she was asking questions and she wanted students to respond to these questions. Roger's experience was somewhat different. In his case, while "the participation from the instructors was very high.... The participation from the students was not". In fact, he believed, 
especially regarding his second session, that it was "much too instructor dominated." He admitted that the instructors "didn't give the students much of an opportunity to talk" and instead, students "were listening for an awful lot of the time." He did not recall any instances of longer discussions about any particular topic. Roger expressed his dissatisfaction with students" lack of opportunity for input by concluding that "it probably wasn't the most enriching experience all the time listening to instructors ramble on." As a solution, he proposed classes with small groups of students and one instructor. He believed that such arrangement would allow for "an in depth discussion" and increase the potential of ELive to be "much more interactive".

Janice explained that, because she was "a pretty good talker," she tended to speak more than the students during the sessions. She noted that, because of this tendency, she may have "filled up the dead space" that might have occurred otherwise. She also explained that she may have "talked too much" because of the "tight agenda" driven by the amount of course content. Audrey reported that, in her case, the patterns of communication changed by the third session. In that session, "there was some... conversation student to student as opposed to student and me and then student and me and then another student and me." She attributed this change to the fact that it "takes a while for people to get used to that format and communicating that way." David explained that, in his case, he "tried to discipline" himself "not to dominate the talking." He wanted to avoid "one way communication", or "a one way presentation". He concluded that, if he were to hold teacher centred sessions, he "might as well just put [the] notes online" and that he was "not sure what the point of that would have been."

\section{Whole groups versus breakout groups}

With one exception, instructors used ELive for whole group sessions. They did, however, recognise the advantage of small group discussions in the breakout rooms. Roger and Janice worked with the largest group (44) of the eight instructors using ELive. Roger's perception of the experience was that students had few opportunities for input and interaction, which he saw as "a bit of a drawback". He commented that, although the students could ask questions, a lot of them "sat there listening for the whole... two hour session". Audrey's perception of the number of students who can effectively participate in a synchronous session was that "it really depends what you're using it for". She clarified that, if she were using it for practicum supervision or program development, "a tutorial of six would be nice, ten would be max.... It's different for a presentation." 
To promote participation with larger groups, David used the breakout rooms feature of ELive to allow students to have discussions in smaller groups. He found this feature to be an effective means of engaging students. David explained that he could visit each of those rooms when students were working in groups and he was "quite delighted to find... everybody taking part" in the discussion. Other instructors did not use the breakout rooms due to a lack of time and because the types of discussions lent themselves to the whole group listening.

\section{Discussion}

Instructors' experiences of using DM in conjunction with two-way audio highlighted the tensions that arose because of competing priorities. Troubleshooting using DM was vital yet sometimes interfered with or interrupted teaching and forced instructors to divide their attention between one priority or the other. Likewise, the private conversations were useful for promoting students' social interaction in an online environment yet distracted some instructors. Balancing course related versus unrelated communication among students became problematic in some cases. A tension or conflict arose for some instructors between the need to impose rules around the use of DM, and a desire to allow them to interact socially.

In their investigation of synchronous audio communication in distance language courses, Hampel and Hauck (2004) refer to text messaging as a supplement to the audio input. Pullen (2004), who described use of synchronous communication in university courses, highlighted the value of text messaging when integrated with voice communication. He noted that DM provides an additional channel of communicating about course related as well as technical issues. In their study of synchronous chats in a university setting, Schwier and Balbar (2002) found that students were "passing notes" during the public discussion (p.31). The authors report that the majority of these side conversations were purely social. Although it was sometimes distracting, Schwier and Balbar plan to encourage side talk in the future since it also helped reduce the feeling of isolation among students. Instructors in Pullen's (2004) study encouraged the use of text messaging for content related purposes, by asking students to send them private messages during audio presentations and indicate whether further clarification was needed.

Kinzie, Whitaker and Hofer (2005), on the other hand, recommended against dividing the students' attention during academic instruction. Their study of use of instant text messaging during face to face lectures revealed that both students and instructors found the students' reliance on multiple sources of input distracting. This result confirmed findings in cognitive psychology (e.g. Hembrooke \& Gay, 2003) which strongly suggest that 
performing two tasks simultaneously leads to a lower performance on either one or both of those tasks.

Instructors' experiences of using two way audio highlight issues of student centred versus teacher centred communication. Their descriptions of this experience frequently relied on arguments that paralleled face to face with online synchronous communication, as if the two contexts were no different. Other arguments or explanations which they provided for lack of student participation referred to individual differences between students, group size, the need for patience or prompting strategies, the need to cover course content, and the time needed for students to get used to the new technology.

When contrasting online asynchronous and face to face synchronous communication, Hardless (2000) refers to the active and passive modes of students' engagement as "participation versus presence" (p. 44). Ng and Detenber (2005) note that research suggests that lurkers, or students who merely listen, are likely to eventually become active participants in the discussions. However, in their own study of participation in both asynchronous and synchronous environments, they found that some students remained silent for the duration of the project.

Schwier and Balbar's (2002) investigation of text based synchronous chats highlighted the importance of careful planning and organisation in order to maintain lively discussion and avoid silence in synchronous communication sessions. In order to promote participation and interaction, the authors prepared students for the session by assigning readings and presenting a structure ahead of time. The authors found this strategy helpful in focusing the discussions and maintaining student engagement during the synchronous chats. Likewise, Kearsley (2000) asserts that such use of effective strategies to promote student participation and interaction in online classes is a pivotal task of the instructor and facilitator.

Since, in any classroom situation, some students will be more active than others, Schwier and Balbar (2002) suggest that instructors may want to "nudge some people to join the conversation or offer their thoughts" (p.30). De Schutter et al. (2004), however, assert that inviting individual students to speak should be done in a sensitive manner since students' comfort levels with regards to public speaking might vary. They encourage instructors to issue prior "warnings" that the strategy of prompting individual students will be used (p.8).

Anderson (2003) notes that instructors mainly use audio and video conferencing for lecture type delivery of content. He further argues, however, that, in order to increase the potential for learning, instructors 
need to promote various forms of interaction, including student-student, instructor-student, and student-content (Anderson, 2003; Dykes \& Schwier, 2003). Dykes and Schwier (2003), in their study of online synchronous chats, accomplished this task by ensuring "that the strength of the instructor's voice didn't drown out other voices or dominate discussions" (p.25).

De Shutter et al. (2004) argued that the success of any online discussion is highly dependent on the number of participants. The authors added that, with a large group, information exchange is likely to be ineffective. They found that, to ensure a meaningful discussion in the context of audio synchronous communication, the number of students should be lower than 15. Macleod (2000) suggests even smaller numbers and claims that six to eight students would be ideal to maintain students' active engagement in a synchronous audio environment.

When conducting synchronous sessions with a small number of students at a time is not feasible, dividing students into smaller groups is an advisable strategy (De Shutter et al.; 2004, Lobel et al., 2004; Macleod, 2000). Dykes and Schwier (2003), in a context of synchronous, text based communication, found it necessary to divide their group of 16 students into two. Not only does dividing the group allow for more meaningful communication, it also contributes to student satisfaction. Students in Lobel et al.'s (2005) study of a university course involving a blended face to face and text based synchronous environment reported that small group discussions contributed to creating a milieu that was "open, accepting, supportive, and collaborative" (p.22).

\section{Conclusions and implications}

The purpose of our study was to gain insight into instructors' experiences with web based synchronous communication using two way audio and direct messaging. The study provided an opportunity to appreciate how instructors experience multiple channels for communication when they are typically used to only asynchronous text based communication and interaction in their distance courses. The first category of direct messaging with its sub-categories of troubleshooting versus teaching, and public versus private conversations, highlighted their experiences with dividing attention. Their experiences revealed how they tried to manage juggling simultaneous attention on communicating via audio while at the same time focusing on text based messages. The juggling involved dividing attention simultaneously between technical, social, and pedagogical aspects of learning. Instructors appeared to be concerned with the latter yet students made use of the text messaging to focus on the technical and social. Dividing attention in this way represented a new experience for the 
instructors, which they have to learn to manage and for which they may need to evaluate their expectations.

The second category of voice based communication or audio conferencing included the sub-categories of talkers versus listeners; patience versus prompting; whole group versus breakout groups; and two way versus one way communication. These four sub-categories have in common that they relate to audio conferencing. Yet, they also have in common that they each raise issues of promoting student interaction in a context of web based, synchronous audio conferencing. The experiences suggest that it was the instructors themselves and not students who largely made use of the audio features. The exception to this was in the case of one instructor's use of breakout rooms. The study's design did not allow us to determine if the tendency towards instructors' predominant use of the audio tool was a result of a technical or pedagogical shortcoming. The version of ELive being used when the study was conducted supported only two way audio and allowed only one person to talk at a time. This setup and restriction may have favoured a one to many broadcast or teacher centred form of interaction. More recent versions of the software (e.g. ELive Academic Edition Version 7) do, however, support up to four simultaneous speakers. Given this new technical feature combined with pedagogical strategies that rely on use of breakout rooms, every student in a class could have access to their own microphone.

Our study relied on use of Version 6 of the software. In a case of a similar study in which students are grouped in breakout rooms with their own microphone and access to DM, the categories of findings would likely be very different. Likewise, we focused only on ELive as one type of synchronous communication environment. Other environments with different features or even different interfaces might result in behaviours and findings different from what was revealed in our study. We did not consider students' experiences in this environment nor did we conduct any observations of interaction and communication in the classes of the participating instructors. A focus on student perspectives and/or observations would have allowed for triangulation in order to validate the instructors' interview comments. These limitations combined with the findings of this study make evident the need for more investigations of learning and interaction in online synchronous communication environments combining both voice based and text based interactions.

\section{Implications for research}

The studies cited in the discussion section of this paper suggested arguments both for and against use of DM, making evident that while social interaction may be desirable in an instructional context, it 
nonetheless requires dividing attention, and this may negatively affect learning. This perspective points to a need for particular investigations focused on the role of direct or instant messaging in contexts where it is used in conjunction with other communication tools such as audio conferencing. Case studies might highlight examples of best practices in balancing the social and technical use of DM in different contexts of instruction. Do some instructional contexts or formats such as the presentation or tutorial support use of DM for social purposes more than other formats? What types of rules, restrictions, or guidelines might simultaneously support both social and instructional goals? In relation to the issue of divided attention, more empirical investigations are needed of new learning environments and particularly with generations of learners accustomed to environments where they are involved simultaneously in multitasking with online gaming, ICQ and email. Use of breakout rooms with small groups using a student and not a teacher as moderator might alleviate or even eliminate the problems identified by instructors in relation to use of DM. This is a hypothesis that might be investigated in future studies.

In relation to the use of two way audio, instructors' reliance on comparisons of online synchronous communication with face to face communication reveals an assumption that students will behave similarly in each environment. This assumption supports the argument that online, just as in a face to face context, some students may lurk, be passive, and remain silent while others talk freely, are active and participate consistently. This assumption that compares the two contexts should not go unchallenged. Indeed, we may ask why some individuals do not participate actively in an online synchronous environment. Is their behaviour merely a mirror image of how they would react in a face to face environment or do they actually behave differently when online? If they do behave differently online, what conditions, contexts, or factors influence or drive that behaviour? For example, are they quiet because they are uncomfortable with the tools needed to communicate actively? Are they quiet because they are in fact taking advantage of the absence of the physical presence to engage in other activities while participating in class? In contexts of audio conferencing, what are the learners doing in the background when they are not actively talking or involved in the discussion?

\section{Implications for practice}

The instructors' experiences suggest that they may have benefited from additional training in the use of ELive. The only training in which they did participate focused on developing a comfort level with the technology and not the pedagogy. Pedagogical training might have focused on strategies or 
best practices for promoting more student participation in this type of communication environment. Also, the training might increase comfort levels with use of breakout rooms and allow them to explore how use of the rooms could be integrated into their planning. Scaffolding techniques could be explored and experimented with to ensure more equal and active participation by students in the use of the audio tool.

The instructors may also have benefited from training in the use of DM. Those interested in the use of this tool in an environment which simultaneously supports audio conferencing need knowledge of strategies and techniques related to its effective use. The instructors' experiences suggest that management of DM requires pre-determined expectations about how the tool can be effectively used in an instructional context. Instructors will need to decide if and to what extent they want to encourage or allow use of DM for social interaction in the context of instructional use. They will need to develop multitasking strategies to manage simultaneous text based and voice based communication. Likewise, instructors may wish to explore strategies and techniques that rely on DM to support private text based communication with students in combination with whole group communication using audio conferencing.

\section{Acknowledgements}

We would like to thank all instructors who participated in this study. We would also like to thank Distance Education and Learning Technologies, Memorial University, in particular Albert Johnson and Glenn Gleeson.

\section{References}

Anderson, T. (2003). Getting the mix right again: An updated and theoretical rationale for interaction. International Review of Research on Open and Distance Learning, 4(2). [viewed 20 Oct 2005]

http: / / www.irrodl.org/ content/v4.2/ anderson.html

Anderson, T. \& Rourke, L. R. (2005). Videoconferencing in kindergarten-to-grade 12 settings: A review of the literature. [viewed 26 2005, verified 18 Feb 2007] http: / / www.vcalberta.ca/community/litreview.pdf

Charmaz, K. (2000). Grounded theory: Objectivist and constructivist methods. In N. K. Denzin \& Y. S. Lincoln (Eds.), The Handbook of Qualitative Research (pp. 509538). Thousand Oaks, CA: Sage Publications.

Chou, C. (2002). A comparative content analysis of student interaction in synchronous and asynchronous learning networks. Proceedings of the Thirty-fifth Annual Hawaii International Conference on System Sciences (HICSS'02), Vol. 5, Washington, DC, IEEE Computer Society. [viewed 13 Oct 2005] http:/ / csdl2.computer.org/comp/ proceedings/hicss/2002/1435/05/14350134b.pdf 
Coghlan, M. (2004). How important are synchronous tools in web-based teaching and learning environments? [viewed 23 Oct 2005, verified 18 Feb 2007] http: / / users.chariot.net.au/ michaelc/synch/surv_discuss.htm

De Schutter, A., Fahrni, P. \& Rudolph, J. (2004). Best practices in online conference moderation. International Review of Research in Open and Distance Learning, 5(1). [viewed 12 Oct 2005] http:/ / www.irrodl.org/index.php/irrodl/article/view/164/ 245

Dykes, M. E. \& Schwier, R. A. (2003). Content and community redux: Instructor and student interpretations of online communication in a graduate seminar. Canadian Journal of Learning and Technology, 29(2). [viewed 24 Oct 2005, verified 18 Feb 2007] http:/ / www.cjlt.ca/ content/vol29.2 / cjlt29-2_art-4.html

Elluminate Live (2001-2006). The Elluminate Live environment. [viewed 7 Oct 2006, verified 18 Feb 2007] http: / / www.elluminate.com/support/orientation5/te_vc.jsp

Glaser, B. G. (1992). Basics of grounded theory analysis. Mill Valley, CA: Sociology Press.

Hampel, R. \& Hauck, M. (2004). Towards an effective use of audio conferencing in distance language courses. Language Learning $\mathcal{E}$ Technology, 8(1). [viewed 20 Oct 2005] http:/ / llt.msu.edu/vol8num1/hampel/ default.html

Hardless, C. (2000). Net-based learning in higher education. Göteborg, Department of Informatics. [viewed 24 Oct 2005] http: / / www.handels.gu.se/epc/archive/ 00001918/01/christianhardlessIA7400.pdf

Hembrooke, H. \& Gay, G. (2003). The laptop and the lecture: The effects of multitasking in learning environments. Journal of Computing in Higher Education, 15(1). [viewed 24 Oct 2005]

http: / / www.hci.cornell.edu/LabArticles / Multitasking_Hembrooke.pdf

Hrastinski, S. (2005). Introducing a synchronous medium in a computer-mediated distance learning course: Towards understanding how student participation is affected. Proceedings ASCILITE 2005, Brisbane. [viewed 24 Oct 2005] http: / / www.ascilite.org.au/conferences/brisbane05/blogs/proceedings/ 30_Hrastinski.pdf

Kearsley, G. (2000). Online education: Learning and teaching in cyberspace. Belmont, CA: Wadsworth/Thomson Learning.

Knolle, J. W. (2002). Identifying the best practices for using HorizonLive to teach in the synchronous online environment. Master's Thesis, California State University, Chico. [viewed 12 Oct 2005]

http:/ / www.csuchico.edu/ jknolle/research/thesis/Knolle_Thesis.pdf

Kinzie, M. B., Whitaker, S. D. \& Hofer, M. J. (2005). Instructional uses of instant messaging (IM) during classroom lectures. Educational Technology \& Society, 8(2), 150-160. [verified 18 Feb 2007] http:/ / www.ifets.info/journals/8_2/14.pdf 
Levy, M. \& Kennedy, C. (2004). A task-cycling pedagogy using stimulated reflection and audio-conferencing in foreign language learning. Language Learning $\mathcal{E}$ Technology, 8(2), 50-68. [viewed 13 Oct 2005]

http: / /llt.msu.edu/vol8num2/levy/default.html

Lobel, M., Neubauer, M. \& Swedburg, R. (2005). Selected topics from a matched study between a face-to-face section and a real-time online section of a university course. International Review of Research in Open and Distance Learning, 6(2). [viewed 12 Oct 2005]

http: / / www.irrodl.org/index.php/irrodl/article/view/234/319

MacLaughlin, E. J., Supernaw, R. B. \& Howard, K. A. (2004). Impact of distance learning using videoconferencing technology on student performance. American Journal of Pharmaceutical Education, 68(3), article 58. [verified 18 Feb 2007] http: / / www.ajpe.org/aj6803/aj680358/aj680358.pdf

Macleod, H. (2000). Audio conferencing guidelines. [viewed 20 Oct 2005, verified 18 Feb 2007] http:/ / www.gla.ac.uk/lncs/main/AUDIO.HTM

Murphy, K. J. \& Collins, M. P. (1997). Communication conventions in instructional electronic chats. First Monday, 2(11). [viewed 11 Oct 2005, verified 18 Feb 2007] http:/ / www.firstmonday.dk/issues/issue2_11/murphy

$\mathrm{Ng}$, E. \& Detenber, B. (2005). The impact of synchronicity and civility in online political discussions on perceptions and intentions to participate. Journal of Computer-Mediated Communication, 10(3), article 4. [viewed 26 Oct 2005, verified 18 Feb 2007] http:/ / jcmc.indiana.edu/vol10/issue3/ng.html

Nicholson, S. (2002). Socialization in the ‘virtual hallway': Instant messaging in the asynchronous web-based distance education classroom. Internet and Higher Education, 5(4), 363-372. [verified 18 Feb 2007] http: / / dlist.sir.arizona.edu/735/01/virthall.pdf

Nobes, C. (2003). An examination of an alternative mode for synchronous discussion in distance education. Proceedings NAWeb 2003. The University of New Brunswick, Canada, 18-21 October. [viewed 12 Oct 2005, verified 18 Feb 2007] http: / / naweb.unb.ca/ proceedings / 2003/PaperNobes.html

Pullen, J. M. (2004). Synchronous internet distance education: Wave of the future or wishful thinking? Proceedings of the 2002 E-Technologies in Engineering Education Conference, 11-16 August 2002, Davos, Switzerland. [viewed 25 Oct 2005, verified 18 Feb 2007] http:/ / services.bepress.com/cgi/viewcontent.cgi? article $=1028 \&$ context $=$ eci $/$ etechnologies

Schwier, R. A. \& Balbar, S. (2002). The interplay of content and community in synchronous and asynchronous communication: Virtual communication in a graduate seminar. Canadian Journal of Learning and Technology, 28(2). [viewed 12 Oct 2005] http: / / www.cjlt.ca/content/vol28.2/schwier_balbar.html 
Slack, F., Beer, M., Armitt, G. \& Green, S. (2003). Assessment and learning outcomes: The evaluation of deep learning in an on-line course. Journal of Information Technology Education, 2, 305-317. [verified 18 Feb 2007] http: / /jite.org/ documents/Vol2/v2p305-317-29.pdf

Strauss, A. L. \& Corbin, J. (1998). Basics of qualitative research: Techniques and procedures for developing grounded theory. Thousand Oaks, CA: Sage.

Yin, R. (2003). Case study research: Design and methods. Thousand Oaks, CA: Sage Publications.

Elizabeth Murphy is an Associate Professor of educational technology and second language learning in the Faculty of Education, Memorial University, Newfoundland, Canada. Her research focuses on secondary and post-secondary distance education, content analysis of online discussions and technology mediated language learning.

Justyna Ciszewska-Carr is a student at the Faculty of Education, and an instructor at the Department of English at Memorial University of Newfoundland. Her research interests include the use of technology in teaching and learning, as well as issues related to working with linguistically and culturally diverse students.

Faculty of Education, Memorial University of Newfoundland St. John's, NL Canada A1B 3X8.

Email: emurphy@mun.ca, justyna_ciszewska@yahoo.com 